\title{
Perceptions of broadcast and film media practitioners in UK higher education
}

\author{
John Mateer* - University of York, UK
}

\begin{abstract}
With a growing emphasis on employability and commercial relevance, universities are increasingly involving practitioners in delivery to add perceived value and credibility to their film and television courses. Likewise, film education researchers, including Bergala (2016), see significant value in practitioner involvement in teaching. Yet, from both the academic and industry sides, this integration has been questioned and challenged, resulting in a long-standing discussion of the 'theory/practice divide'. Through analysis of two formal surveys conducted in 2012 and 2014, involving 131 respondents from 64 UK higher education institutions, this paper reports on the perceptions of broadcast television and film practitioners working in academia. It also briefly considers whether the issues raised have changed since the surveys were completed. Responses suggest that an appreciable number of respondents encountered a mixed or negative reaction from new academic colleagues immediately upon joining their institution, and that this has had a potentially lasting negative impact on their productivity. The data indicate that many media practitioners working in higher education do not feel that they are seen as equal to non-practitioner colleagues, although they do still feel part of the academy as a whole. Respondent institutions were broken down by type, and there is statistically significant evidence of perceptions of systematic disadvantaging of media practitioners across all types of UK academic institutions, although Arts-focused universities were seen most favourably. This suggests that, despite the UK government's increased emphasis on teaching and employability, and new commercially focused research funding initiatives, higher education institutions need to do more to redress the perception of a theory/practice divide.
\end{abstract}

Keywords: academic life; theory/practice divide; conditions of practice; media practitioners in education; film education

\section{Introduction}

The importance of the involvement of practitioners in media education has been touted since the emergence of formalized cinema, with Lev Kuleshov being but one of a number of early proponents of the integration of theory and practice in the early 1920s (Petric, 1974). Indeed, many pioneers in the development of film theory, such as Vsevolod Pudovkin and Sergei Eisenstein of the Soviet school, and Louis Delluc and Jean Epstein of the French Impressionist movement, were also seminal film-makers. Within current theoretical debates concerning the fundamental nature of film education, as exemplified (and arguably prompted) by Bergala's The Cinema Hypothesis (2016), the making of films is seen to be as potentially important as analysis in understanding the film medium. Bergala argues that 'The two approaches require and nourish each other' (BFI Southbank, 2017), and the involvement of practitioners is seen as a key 
component in this process. On a commercial level, the creative industries, including film and television, are playing a significant economic role, currently contributing over $f 90$ billion per year to the British economy alone (Clark in DCMS and BEIS, 2018). With the government's growing emphasis on employability and commercial impact, universities are increasingly employing practitioners to add perceived value and credibility to their programmes. Yet, from both academic and industry sides, this integration has been questioned and challenged, resulting in a long-standing discussion of the 'theory/practice divide'. Indeed, at times this division has been truly combative, as the feud between the noted Australian media historian Keith Windschuttle and lauded practitioner-academic John Hartley in the 1990s illustrates (Crook, 2015).

In 2001, as a film and television industry veteran of more than 15 years at the time, I decided to accept an academic position to assist in the development of a new undergraduate programme that involved production. This proved to be successful to the point that I was then asked to be a founding member of a new media-focused department three years later. On the face of it, my participation in both endeavours would suggest that I was accepted as an equal member of the academy despite previously having an industry-only background. However, both my initial appointment and subsequent involvement in the development of a department were met with scepticism (and even contempt) by some academic colleagues. There was also scepticism from industry contacts, who felt that my involvement in academia meant that I had left industry - this in spite of my continuing professional activity and fostering of mutually beneficial academic-industry links. In his article, 'Theory for practice: Ceci n'est pas l'épistémologie', Brian Winston (2011: 193) echoes my own feelings: 'For a practice teacher, making one's own way in the academy on the basis of one's professional qualifications alone is ... hard. Continuing to work as a media professional can count for little.'

My experience in academia over the past 18 years led me to wonder whether it was unique, or perhaps particular to my institution, and whether others who entered academia from industry had similar experiences. It also raised the question of whether it might be possible to begin to more formally describe or even quantify the theory/ practice divide beyond the theoretical analyses of Bell $(2004,2006)$, Petrie (2011) or the various scholars in Clive Myer's (2011) seminal compendium Critical Cinema.

Previous research into the involvement of practitioners in media education has tended to be limited in scope or focused on specific aspects of the practitioneracademic experience, rather than considering the role as a whole. Bergala (2016) sees the film-maker in an idealized form as 'artist', and is unashamedly anti-Hollywood, effectively ignoring (if not discounting) the current widespread involvement of mainstream commercial film and television practitioners in teaching. Other film education researchers, including Chambers (2018), Bachmann and Zahn (2018) and Aidelman and Colell (2018), consider different ways that film-makers have been (or can be) involved in the delivery of film education programmes, but do not consider actual practitioner experiences in the process in any significant depth.

Bell (2004) considers his own experience as a film-maker entering the academy in his analysis of the theory/practice divide. He argues that an institutional emphasis on traditional research outputs coupled with a vocational view of media training has served to widen this divide for practitioners working in the academy. Although it provides some very interesting insight, it is primarily a personal commentary. In his later work, Bell (2006) explores more broadly this seemingly contentious relationship between practice and research, an important aspect of the academic role, but only one part of the academic experience. 
Petrie (2011) provides a highly detailed account of how the theory/practice divide has manifested itself in film education, considered at a historical institution-focused level rather than at a personal one. In Myer's (2011) edited volume, the theory/practice divide is examined from a range of perspectives. Of these, Winston's (2011) relates most closely to the questions concerning the experiences of practitioners working in the academy, where he describes his observations of the combative relationship between 'the theory people' and 'the practice teachers', and then considers ways in which theory and practice can be seen as complementary in educating film-makers.

Of the work most directly related to the focus of this article, Parmar (2010) interviewed five active industry professionals seconded to the Bournemouth University Media School as 'teacher-practitioners'. Despite the comparatively small number of participants, this study yielded some interesting insight into differences in expectations of industry professionals entering the academy, as well as their experiences in assimilating into the academic community. Parmar (ibid.) observed that industry professionals often have inaccurate preconceptions about universities, for example that equipment is out of date, and that academics are 'out of touch' with industry practice, but also reported that this group saw benefits of working in the academy, including the ability to work with talented students, which enabled them to reflect on their own practice and develop. However, the way in which academia operates was often seen as slow and bureaucratic when compared with industry. Her conclusion was that experiences were, on balance, more positive than negative for her subject group.

Clews and Mallinder (2010) carried out a broad survey into how the creative industries and higher education (HE) institutions have interacted, and the role of teacherpractitioners in those collaborations. While their study was larger in scale, including interviews with 120 practitioners working with approximately $75 \mathrm{HE}$ institutions across a range of creative disciplines, it was not specifically focused on the experiences of media practitioners entering and working in the academy, but rather on outlining the types of collaborations (placements, industry liaisons and so on) and quantifying the number of departments that employ teacher-practitioners (around 85 per cent, with the majority employed as guest speakers or part-time lecturers).

Ashton (2013) considered the professional identity of media practitioners working in education, and how this can be affected by the need to balance teaching and professional media practice. While his analysis provides some strong insight into the practitioner's experience in the academy, like Parmar's (2010) work, the emphasis of Ashton's (2013) article is to consider how the practitioner-academic's industry experience can help media students gain a sense of identity as 'cultural workers' rather than exploring the challenges encountered by practitioners in academia.

To date, there has not been a large-scale survey of those most directly involved in the theory/practice debate - media practitioners working in higher education. This paper aims to fill that gap by systematically assessing the views and experiences of broadcast television and film practitioners working in UK academia ('film' in this context referring to narrative and non-fiction feature film but not corporate or shortform commercial film-making). It details the results of surveys conducted in 2012 and 2014, then briefly considers whether the issues raised have changed or been addressed as of the start of 2019.

\section{Methods}

Two online surveys were conducted, the first in 2012 and the second in 2014. To recruit appropriate participants for this study, a list of HE-level media production 
undergraduate and postgraduate programmes on offer in the United Kingdom was compiled using information from publicly available sources, including the Universities and Colleges Admissions Service (UCAS), Creative Skillset (now known as ScreenSkills, the UK government initiative that supports focused education to enhance the talent base for media industries) and FindAMasters. At this initial stage of the research, all types of media production programmes were considered. Each programme was then examined through the website of the host institution to determine the backgrounds of staff involved in delivery. Individual biographies were reviewed, with any listed staff members whose background suggested they had paid media industry experience being added to a list of candidate subjects. This provided a subject pool of 215 possible participants from 47 institutions for the 2012 survey, with an expanded search in 2014 yielding an additional 200 for a total subject pool of 415 candidates from 64 institutions across all media production-related disciplines who were directly contacted. Referrals to colleagues were also encouraged, so, while the actual reach of the survey is unknown, it is reasonable to surmise that the list collated represents a substantial sample of the film and television practitioners working in UK higher education at the time the surveys were conducted.

Surveys ran from August to October in 2012 and from June to August in 2014. The surveys were administered through SurveyMonkey, and consisted of a series of multiple-choice questions with text boxes for comments. The 2012 and 2014 surveys are identical apart from an additional section in 2014 designed to evaluate any changes in circumstances or opinions from those participants who had completed the 2012 survey. As the study was conducted completely anonymously, there was no direct way to link responses between the two surveys, but participants were asked if they had completed the survey previously. In both surveys, the option of entering a draw for a $f 50$ voucher was offered as an incentive to help generate interest in the study. Analysis of the data provided by the surveys was completed using analytical tools within SurveyMonkey and Excel.

For the purposes of this paper, the term 'practitioner' is used to mean a media practitioner who has worked in the film and/or television industry on a paid basis in either a creative or technical capacity; 'non-practitioner' is used in reference to an academic who has not worked in these industries and entered work in the academy through a traditional route (for example, advanced degree, research associate position). To preserve anonymity, individual participants are referred to by the number assigned to them by the SurveyMonkey system. The type of HE institution with which respondents are associated will be shown in parentheses when this is relevant to the discussion.

\section{Results}

The 2012 survey resulted in 100 respondents, while the 2014 survey had 150 respondents overall, 13 of whom indicated that they also completed the first survey. This resulted in an overall sample size of 237 individual participants from all media production disciplines across the two surveys - a response rate of 57 per cent based on the numbers originally contacted via email, although there may have been some respondents from outside this group. For the purposes of this study, participants were filtered so that only those who declared having predominantly worked in broadcast television or feature film production were included. This resulted in 65 discrete respondents from 2012 and 66 from 2014 for a total sample size of 131 for this study. 


\section{Participant backgrounds}

The majority of the 131 respondents (89 per cent) had worked in the film and television industry for more than ten years, with only 5 per cent having five or fewer years of experience; 92 per cent stated that they had worked in broadcast television and 50 per cent in feature film; 40 per cent overall reported working in both disciplines.

In terms of time spent working in $\mathrm{HE}, 43$ per cent had worked in academia for more than ten years, 34 per cent between five and ten years, and the remaining 23 per cent for less than five years. None had worked for less than one year (that is, no new appointees responded). Of respondents, 94 per cent indicated that they were not the first practitioner hired by their academic department.

Of respondents, 87 per cent reported that they worked for only one institution, with the remainder being employed by two or more simultaneously. A majority of participants (61 per cent) stated that they were full-time staff with teaching, research and administrative duties, 20 per cent were on full-time teaching-only contracts and 19 per cent were on part-time contracts; 95 per cent of respondents stated that they teach at undergraduate level, 68 per cent at master's level, and 23 per cent reported that they were involved in $\mathrm{PhD}$ supervision.

For this paper, distinguishing between different types of institutions is important in order to determine whether certain institutional attributes (such as age, and whether the university started as a college or polytechnic) or priorities (such as research or vocational training) have had an impact on the experience of their practitioneracademic staff.

The types of institutions in the UK in which the participants were employed are grouped according to mission, as follows:

- Million+ (The Association for Modern Universities) is comprised mainly of 'new universities', including university colleges that were given university status after 1992 (for example, Bournemouth, Edinburgh Napier, Staffordshire, Sunderland). Former polytechnics have also been included in this grouping although some institutions may not formally be members of the Million+ group. These institutions are typically viewed as having more of a teaching emphasis, with less academic time dedicated to research.

- The University Alliance is comprised of a range of newer universities with a stated objective to prepare students for careers in industry and prioritize links with relevant companies. Members include Lincoln, Portsmouth, Salford, South Wales and Teesside. Research is undertaken in these universities, although industry-focused teaching is seen as a priority.

- Arts-focused institutions include general arts universities such as Arts University Bournemouth, Ravensbourne and the University for the Creative Arts, as well as dedicated media schools such as the London Film School, and the National Film and Television School. Teaching relevant to industry is the primary focus here, with few staff members engaging in traditional research.

- Russell Group universities (such as Bristol, Cambridge, Edinburgh, Oxford, Warwick and York) are highly research-intensive and receive the majority of UK government research funding. These are often regarded as 'top-tier' institutions, with particularly high standards for staff performance.

- The 1994 Group was a collection of smaller universities (for example, Goldsmiths, Royal Holloway and Sussex) where research was also seen as a major focus alongside teaching. It was disbanded in 2013 after the first survey was completed, and thus the designation has been retained for the purposes of this study. A 
number of these institutions joined the Russell Group shortly before or after the dissolution.

The results by institutional type are shown in Figure 1, indicating that the majority of respondents were from institutions with a teaching and vocational focus, with only 16 per cent of respondents being from those with more of a research mission (that is, Russell Group and 1994 Group).

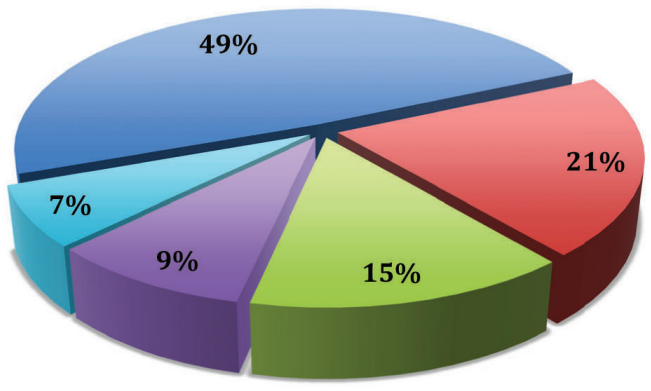

Million+ / Former

Polytechnics

- University Alliance

Arts-focused

Eormer 1994 Group

Russell Group

Figure 1: Results by type of academic institution

\section{Entering the academy}

Participants were given a range of choices for why they entered academia, as well as the option to add their own. These were presented randomly to each participant to avoid biasing responses, and more than one option could be chosen. The results are shown in Figure 2.

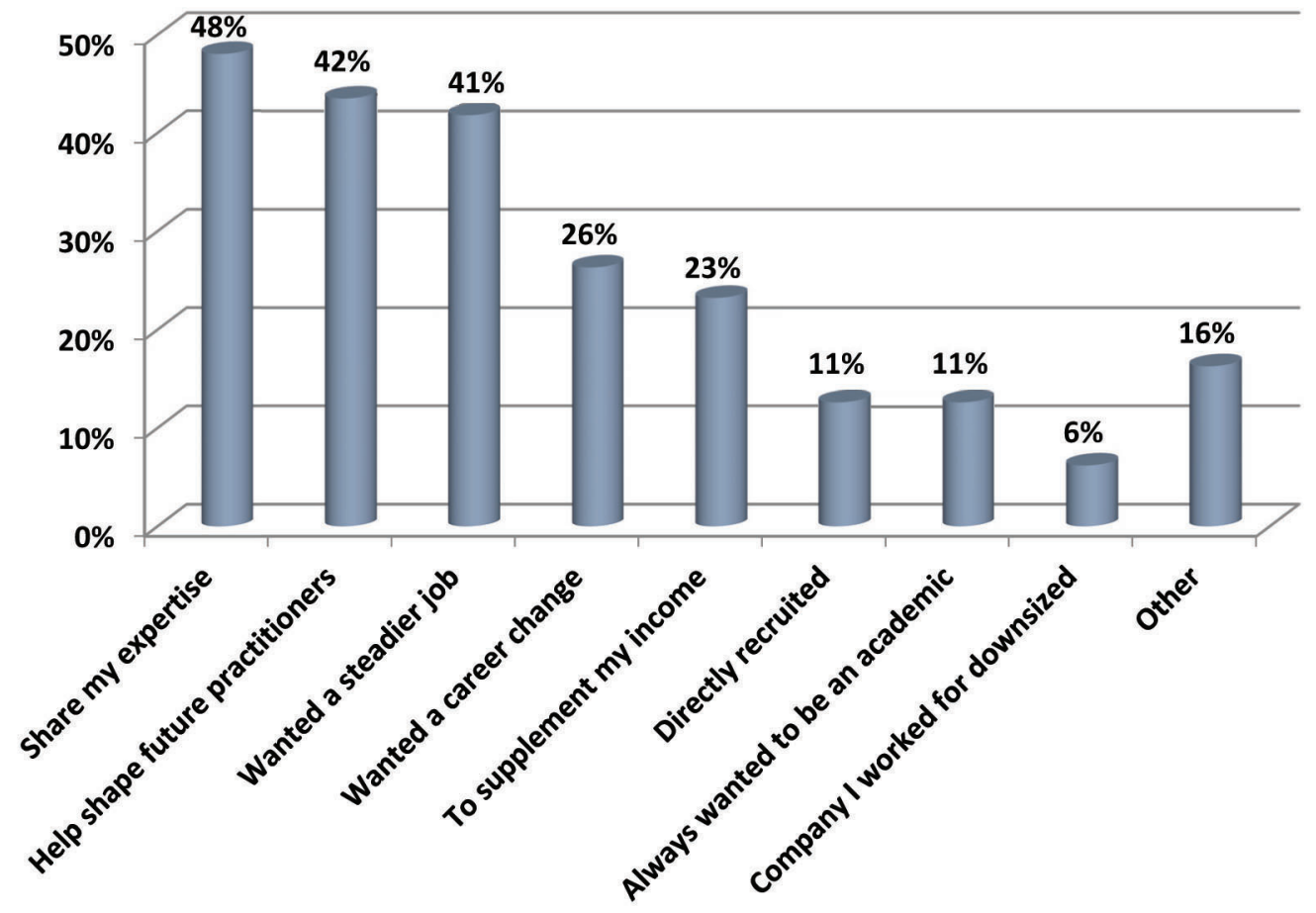

Figure 2: Reasons for entering academia 


\section{Participant impressions of how they were viewed within their} institutions

When asked about the initial reaction from non-practitioner colleagues upon their appointment, most but not all said they were welcomed warmly, as shown in Figure 3 .

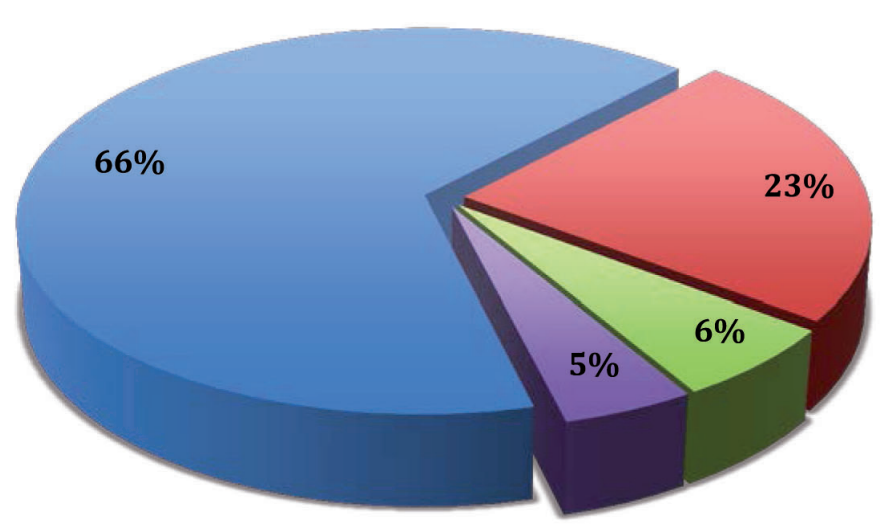

I was welcomed warmly by everyone

I I was welcomed politely but sensed scepticism among some colleagues

I got the distinct sense that I was not seen as the right person for the job

\section{I do not remember}

Figure 3: Initial reactions of non-practitioner colleagues

Participants were also asked about their perception of how they felt they were viewed by non-practitioner colleagues in their institutions, and results are shown in Figure 4.

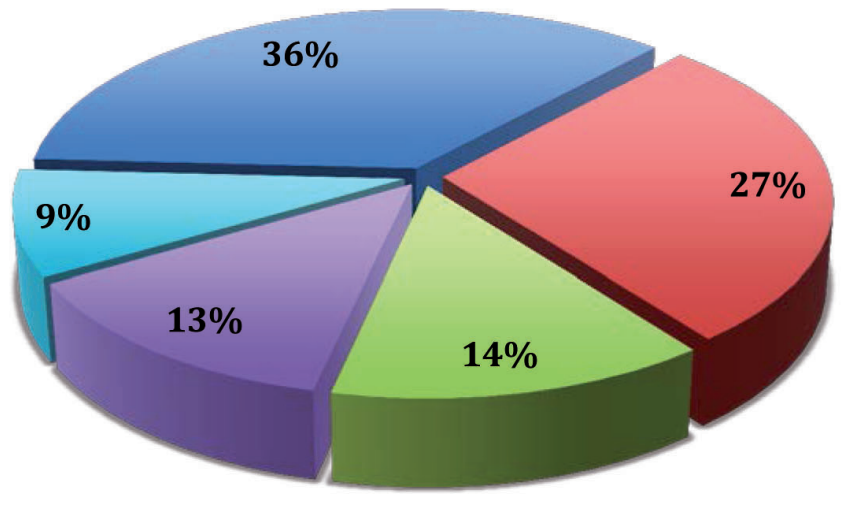

Seen as an equal in some respects but not in others (e.g. researcher, scholar, etc.) - Seen as an equal in all respects

Held in higher esteem than some colleagues given my experience as a practitioner - Held in lower esteem than some colleagues given my involvement in industry I have never thought about it

Figure 4: Views of non-practitioner colleagues

To gain insight into the possible reasons for any perception of inequality, participants were asked whether they felt their institutions valued staff on 'teaching only' or 'teaching and scholarship' contracts as highly as those who had research as part of their job description. In response, only 19 per cent felt that they were valued equally, whereas 55 per cent felt that they were not; 26 per cent had no opinion or indicated that this was not relevant to their institution. When asked whether they themselves felt staff on teaching-only or teaching and research contracts make an equal contribution to their institutions, 59 per cent said that they did and 15 per cent stated that they did not, with 26 per cent expressing no opinion.

When asked whether they felt part of the academic community, 69 per cent responded that they did, with 31 per cent stating that they did not. Some 64 per cent of participants felt that the staff make-up of their department had a 'good balance of 
practitioners and non-practitioners', while 33 per cent argued that there should be more practitioners on staff, and 3 per cent stated that there should be more nonpractitioners in their department. All but one respondent stated that they felt the involvement of media practitioners in teaching enhances the student experience.

Respondents were able to comment on all of the questions for this section. These responses are explored in the 'Analysis and discussion' section below.

\title{
Research activity
}

Despite the fact that most respondents were from institutions with a teaching and vocational focus, and irrespective of the type of academic contract held, 74 per cent of participants claimed to be research-active - three-quarters of those reported this as part of their academic job and a quarter as an independent activity. Of the remaining participants, 16 per cent stated that they intend to undertake research at some point, while 10 per cent did not expect to conduct any form of research.

There are several types of activities undertaken as research, outlined below:

- 'Research by Practice' refers to both media-based works that are contextualized for academic dissemination, and commissioned industry work that is accepted by the respondent's academic institution as formal research. This is discussed in greater detail below.

- 'Traditional Scholarly' refers to work based on literature and academic research, such as that published in film studies, educational or other 'traditional' academic journals.

- 'Knowledge Transfer' refers specifically to research conducted as part of a formal Knowledge Transfer Partnership scheme (for example, through Innovate UK/ Technology Strategy Board) between the respondent's academic institution and a commercial partner.

- 'Traditional Scientific' refers to technically based research, such as software or systems development, as published in mathematics or engineering journals.

- 'Commercially Funded' research refers to work funded solely by a commercial entity for commercial use.

The types of research undertaken by participants are shown in Figure 5.

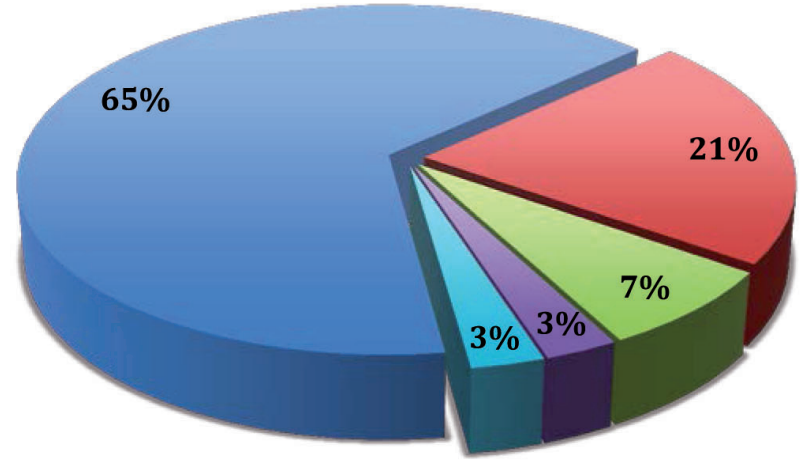

\author{
- Research by Practice \\ Traditional Scholarly \\ Knowledge Transfer \\ - Traditional Scientific \\ Commercially Funded
}

Figure 5: Primary type of research conducted

Participants were asked how they perceived their research to be valued by their institution. This was specifically to try to ascertain whether research undertaken by practitioners is seen differently to that conducted by more traditional academics. While 
36 per cent stated that they felt their research work was seen to be equal to other types of research, 48 per cent said that it was perceived as less important. Only 3 per cent felt that it was regarded as more important, with 13 per cent being unsure. Of those engaged in Research by Practice, 60 per cent of respondents reported that they did not feel this type of research was well understood by their academic institution.

\section{Involvement with industry while working in the academy}

Alongside working in $\mathrm{HE}$, 65 per cent of participants were still active in industry, either on a directly paid or indirectly paid basis (where commercial activity is directly linked to research). Of those, 75 per cent responded that they had to alter their work in industry around their academic commitments, and 52 per cent stated that their academic institution did not make any adjustments to enable them to undertake industry work.

Industry-active respondents were asked how they felt they were viewed by their media industry colleagues, given their work in academia. Results are shown in Figure 6.

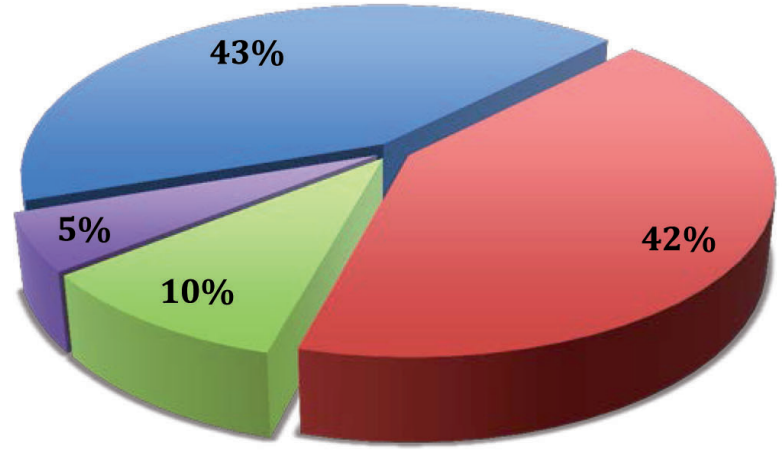

\section{- Some people look at it positively, others do not understand why I joined academia}

nenerally positively

$\square$ I never thought about it

- Generally negatively

Figure 6: Viewed by industry colleagues

Of the 35 per cent who responded that they were no longer active in industry, 61 per cent reported that academic work took too much time, 26 per cent responded that they could not get suitable or consistent work, 17 per cent stated that changes in the film and television industry made it less attractive to continue with commercial work, and 17 per cent noted that they had accomplished what they wanted in industry (respondents were able to choose more than one option).

Participants were invited to comment, and their responses are discussed further in the 'Analysis and discussion' section below.

\section{Future plans}

A small majority of respondents (53 per cent) stated that they planned to continue working in both academia and industry, 22 per cent expected to leave industry completely, while 8 per cent were looking to leave academia to return to industry; 17 per cent were unsure.

Two additional questions were posed in the 2014 survey. The first followed up on the preceding question to determine whether the participants' plans had changed during their time in academia. While 55 per cent stated that they had not, 29 respondents (45 per cent) said that they had. Reasons given are shown in Figure 7. Note that some 'Other' responses actually indicated available answer options and so were combined with those. 


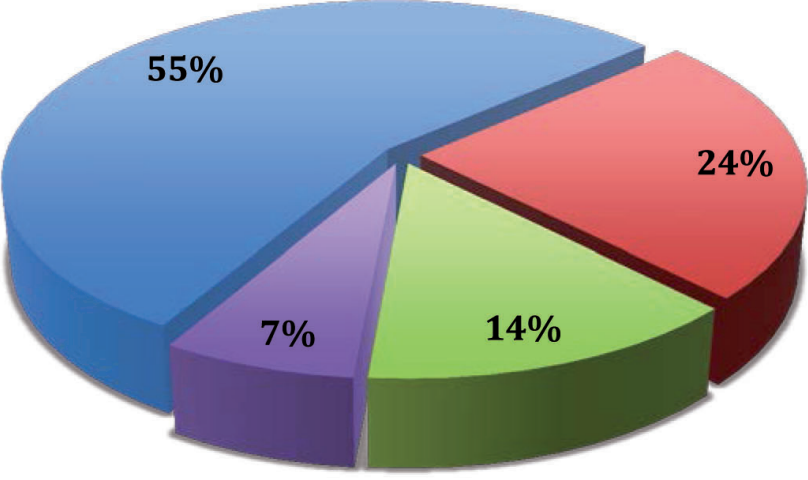

Due to changes in my academic institution

Due to changes in the film and TV industry

Academia is not what I expected it to be

nother

Figure 7: Reasons for change in future plans

The second additional question in the 2014 survey looked at whether or not respondents had changed institutions during their academic career - 57 per cent had not. Of the 32 participants (43 per cent) who had moved academic institution, the reasons given are shown in Figure 8.

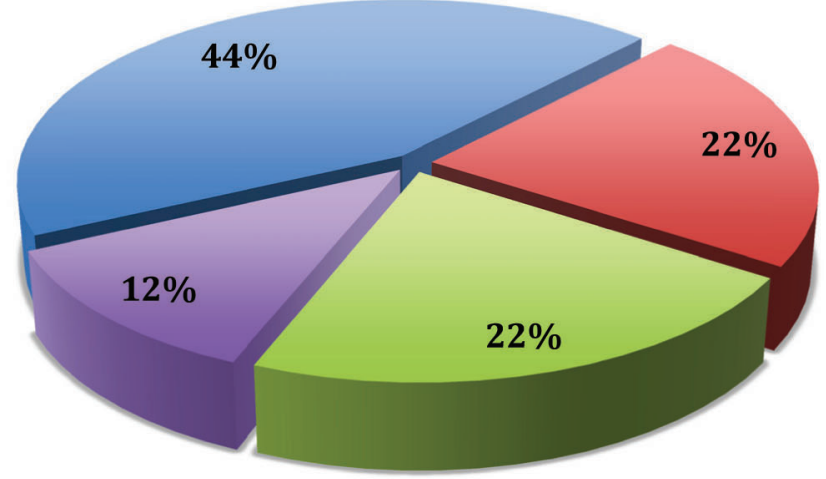

\section{Eavourable contract change or situation}

Better ability to work as a practitioner

Location of institution

¿ Unfavourable contract change or situation

Figure 8: Main reasons for changing HE institution

\section{Analysis and discussion}

The main results of the surveys are analysed and discussed in this section. This includes free-text responses at the end of both surveys that allowed participants to add general comments; 26 per cent (34 people) did so, many leaving lengthy entries that give insights into the experiences of media practitioners in their institutions.

\section{Entering the academy}

From the surveys it is clear that the media practitioners who participated entered academia for two main reasons, broadly speaking:

1) Economic - 54 per cent of all respondents selected 'to have a steadier job', 'supplement their income' and/or 'the company I worked for downsized or went out of business'.

2) Altruistic - 59 per cent of all respondents selected 'to share professional expertise' and/or 'shape the next generation of practitioners'. 
The first point is telling, and may be indicative of changes and new demands in industry that have forced practitioners to reconsider their career trajectories, as discussed by Dex et al. (2000) and Hesmondhalgh and Baker (2010). Also, while Clews and Mallinder (2010) found that a majority of practitioners in their survey of creative industries were employed part time, 80 per cent of respondents to this study were on full-time contracts, which may again indicate increased instability in the film and television industries. These quotes are indicative of a number of respondents' views:

I reached a point, as a district reporter working from home, at which I felt the diminishing professional rewards no longer helped me cope with the stresses of my job; and at 50, I could not see a way to progress within the BBC. (Respondent 3347191577)

[I] needed a career which was not as erratic as working in television - better work/life balance with family life. (Respondent 3323998097)

If you have children it is very difficult for both yourself and your partner to maintain a career in the industry. (Respondent 3329162357)

The last comment hints at the issues many women working in the creative industries face. Dent (2016) explores this in detail, highlighting ongoing issues and complexities surrounding the nature of inequality in the media industry. It is beyond the scope of this article to explore these in detail, but they are certainly worthy of further investigation in consideration of the practitioner-academic experience.

The altruistic nature of the second reason given for entering HE (sharing expertise), coupled with comments made by several respondents, suggests that many practitioners entering the academy may have a somewhat idealistic view of academia, seeing it as being less constrictive than industry and allowing greater creative flexibility:

[I] wanted freedom to pursue my own creative projects rather than work on someone else's. (Respondent 1940989196)

[I] wanted to make film work freed up from the treadmill of making I was on at the BBC. In the last 10 years I've made work for BBC Radio/TV but at my own pace and projects I choose or nurture myself. (Respondent 1934540539)

I wanted to be able to put the work that I had done so far into some sort of academic framework in order to move forward. (Respondent 3322319460)

However, actual experiences within the academy were often reported to be different than expected, which has the potential to impact on the ability of practitioners entering academia to assimilate, thus ultimately affecting motivation and performance.

\section{Participant impressions of how they were viewed within their institutions}

Responses suggest that an appreciable number of respondents encountered a mixed or negative reaction from new academic colleagues immediately upon joining their institution. While 66 per cent of participants overall responded that they were 'welcomed warmly' when they first met their academic colleagues, nearly 30 per cent either 'sensed scepticism among some colleagues' or 'got the distinct sense that nonpractitioner colleagues did not feel [they were] the right person for the job'; there was 
little difference between the responses from 2012 and 2014 (27 per cent and 31 per cent respectively for these choices). Perceptions of participants in specific types of institutions are shown in Table 1 (removing those who answered 'Don't remember').

Table 1: Percentage of respondents receiving a positive welcome by institution type

\begin{tabular}{lc}
\hline Institution type & $\begin{array}{c}\text { Respondents } \\
\% \text { (number) }\end{array}$ \\
\hline Arts-focused & $94(16$ of 17$)$ \\
Russell Group & $78(7$ of 9$)$ \\
University Alliance & $73(19$ of 26$)$ \\
Million+ & $65(39$ of 60$)$ \\
Former 1994 Group & $36(4$ of 11$)$ \\
\hline
\end{tabular}

The values above vary appreciably between institution types, and there is a statistically significant difference from what would be expected by chance (chi-square=11.5, $p=0.02$ ). It would appear that Arts-focused universities have been more welcoming of practitioners than other types of institutions, and Former 1994 Group members less so. Considering the work of Petrie and Stoneman (2014), this may be explained by the fact that art schools were among the first to offer film production courses, and have traditionally seen practice as a key element of research across all artistic disciplines.

The finding that nearly 30 per cent of respondents perceived a negative 'welcome' is remarkable given that there is ample research (for example, Ashforth, 2000) indicating that organizations typically try to be attractive and welcoming to new employees, thus creating a 'honeymoon period' (Boswell et al., 2005). Not only are negative experiences at such an early stage dispiriting, but established research into the impact of organizational socialization suggests that these respondents may immediately have been disadvantaged in their ability to undertake their responsibilities effectively, if the perception of a lack of collegial support was experienced from the start (Feldman, 1981; Jokisaari and Nurmi, 2009; Lodahl and Kejner, 1965; Vroom, 1962). As Feldman (1981: 314) notes:

At the encounter stage, initiation to the task and initiation to the group will be correlated ... many recruits report feeling that until such time as they became friendly with co-workers and could trust them, they could not find out information that was essential to doing their jobs well.

Table 2: Percentage of respondents receiving a positive reception from non-practitioner colleagues by institution type

\begin{tabular}{lc}
\hline Institution type & $\begin{array}{c}\text { Respondents } \\
\% \text { (number) }\end{array}$ \\
\hline Arts-focused & 88 (14 of 16) \\
University Alliance & $46(12$ of 26$)$ \\
Million+ & $40(21$ of 53$)$ \\
Russell Group & $33(3$ of 9$)$ \\
Former 1994 Group & 33 (4 of 12$)$ \\
\hline
\end{tabular}


While a majority of respondents felt that there was an initially positive reception in their academic institutions, the data suggest that many media practitioners working in HE do not feel that they are seen as equal to non-practitioner colleagues, as shown in Table 2. As with the perception of 'welcome', there appears to be a clear relationship between the type of institution and the participants' views of how they were valued by non-practitioner colleagues, with the vast majority of those in Arts-focused institutions reporting positive experiences compared with less than half across all other types (chi-square=13.3, $p=0.01$ ).

More than half of all respondents overall reported that they were either 'seen as equal in some respects but not others' or 'held in lower esteem'. The comments below are indicative of the frustration that several participants expressed about this:

As I don't do trad[itional] research I am definitely looked down on, and it is very hard to maintain morale. (Respondent 3369057913 (Russell Group))

There is still, sadly, in some quarters a sense that a practitioner who has not undertaken formal research is akin to a monkey pushing a button. (Respondent 2017339242 (Million+))

Non-practitioners have the time to develop research interests and publications which allows them to develop their careers within the institution and elsewhere, while those teaching practice are stuck as teachers. (Respondent 2016843263 (Million+))

Although I am a bona fide academic in terms of degrees, certificates, etc. I have had a constant battle to get the same terms and conditions as others without professional qualifications. (Respondent 1954715118 (Million+))

There remains a persistent habit by our HoD [head of department] to characterize academics with production experience as 'professionals' and quite distinct from academics. It is a false distinction. (Respondent 1954700730 (Russell Group))

It's taken longer to get promotion and although there are equal numbers of practitioners there is one professor of practice as against 5 or 6 theory colleagues. (Respondent 1934341183 (Former 1994 Group))

It is interesting to note the fall-off in positive perception between the initial 'welcome' and subsequent perception of how much respondents felt valued by colleagues, as shown in Table 3.

\section{Table 3: Change in positive perception from 'welcome' to 'views of non-practitioner} colleagues' by institution type

\begin{tabular}{ll}
\hline Institution type & $\begin{array}{c}\text { Change } \\
\% \text { (detail) }\end{array}$ \\
\hline Russell Group & -45 (78\% to 33\%) \\
University Alliance & $-27(73 \%$ to $46 \%)$ \\
Million+ & $-25(65 \%$ to $40 \%)$ \\
Arts-focused & $-6(94 \%$ to $88 \%)$ \\
Former 1994 Group & $-3(36 \%$ to $33 \%)$ \\
\hline
\end{tabular}


This fall-off may be due in part to institutional demands based on a traditional view of the academic role - the Russell Group in particular has historically placed significant value on intensive traditional research - which does not appear to align well with the 'Research by Practice' that the majority of practitioner-academics undertake (discussed in the 'Research activity' section below). This appears to be consistent with the tension that Bell (2006: 85) observes, 'the notion that creative practice itself - with its enthusiasms and confusions, expressivity and sheer immanence - could be the crucible for a process of systematic research investigation, remains a harder sell within the wider academic community.'

Comments suggest that some of the frustration appears to be due to requirements for staff at some institutions to have higher-level academic qualifications, primarily PhDs, for certain types of roles:

We have a serious problem in recruiting suitable academic staff as the university will only consider applicants who have a PhD. However, this is not valued by the students as much as industry experience. Even the willingness to undertake a PhD is no longer acceptable to the HR department. (Respondent 3347201018 (Million+))

Here there is a clear understanding that practitioners are needed, but this is not understood at university level where they insist that all new staff have PhDs (I got in under the wire). This is because they are more interested in their own academic cred[ibility] than the needs of the students. The only way to rise up the pay scale is to get academic qualifications - length of service in the industry is not considered equally valuable. (Respondent 1944580834 (Million+))

There is a major issue facing our university and possibly others in requiring us to recruit only staff who have PhDs. This has prevented us from taking the appropriate people recently. (Respondent 1934983484 (Million+))

The university keeps going on about PhDs and doesn't mention industry awards, etc. (Respondent 1955468867 (University Alliance))

Interestingly, there is also evidence of similar judgements that some practitioners have made towards non-practitioner colleagues, suggesting that some do not value traditional academic skills:

I don't believe there is any point in having non-practitioners teaching practice-based media skills. There is no way to keep up with current practice otherwise. Film theory is fine with pure academics, but not practice. The challenge is to actually get the time to continue to practise once you are in academia because the structure of such does not realize that the practice is necessary in order to properly teach. (Respondent $1934230802($ Million+))

Non-practitioner colleagues are either sceptical of practitioners' lack of pedagogic rigor, or feel insecure teaching a practice they do not have first hand experience of. (Respondent 1940562240 (University Alliance))

I am both practitioner and traditional scholar, and am perceived by practitioner colleagues as 'inferior' in practice, when in fact have a very similar profile to them but with extra academic experience. (Respondent 1942226482 (University Alliance)) 
I don't actually respect much of the research my academic colleagues undertake, I feel it is indulgent and has little impact - at times it appears to be the same notions rehashed to fill conferences with outputs. (Respondent 2022666615 (Million+))

The apparent lack of respect suggested by these comments, from both academic and practitioner sides, is consistent with Winston's (2011: 195) observations, where he states, 'For practice teachers caught in such a position of enforced inferiority, a defensive hostility is a quite natural, and in my view, an excusable reaction.'

However, despite a significant number of participants expressing that they felt they were seen as unequal to non-practitioner colleagues, almost 70 per cent stated that they did feel they were part of the academic community - effectively bona fide academics (shown in Table 4).

\section{Table 4: Percentage of respondents who felt part of the academic community by institution type}

\begin{tabular}{lc}
\hline Institution type & $\begin{array}{c}\text { Respondents } \\
\% \text { (number) }\end{array}$ \\
\hline Former 1994 Group & $83(10$ of 12$)$ \\
University Alliance & $74(20$ of 27$)$ \\
Arts-focused & $72(13$ of 18$)$ \\
Million+ & $67(42$ of 63$)$ \\
Russell Group & $44(4$ of 9$)$ \\
\hline
\end{tabular}

There is no statistically significant difference between the type of institution for this question (chi-square $=4.3, p=0.37$ ), although responses from Russell Group participants are worthy of further investigation, given that it is the only institution type where fewer than half felt part of the academic community (although the small sample size limits the robustness of this finding).

Comments for this question offer few specifics about the possible contradiction between perceptions of acceptance and feeling part of the academic community, although support from fellow practitioner-academics and embracing a perception that they were non-traditional academics may be factors:

[Yes, but] only because we have a lot of practitioners. (Respondent 3346385003 (University Alliance))

Yes - although I'd never describe myself as an academic. I am professor of practice - which means I am a professor through the body of work I have made. I feel uncomfortable using the phrase academic. I am one - but do not use it! (Respondent 1934540539 (University Alliance))

[Yes,] I feel part of my workplace community but the word academic doesn't really mean much to me. (Respondent 2017339242 (Million+))

[Yes, but] it's a struggle. Old attitudes about the inherent superiority of theory/practice persist - not through malice by any stretch, but because research in these areas are more easily recognized and rewarded. Hence the professoriat, for example, is made up entirely of theory/history people. (Respondent 1954700730 (Russell Group)) 


\section{Research activity}

As noted above, nearly three-quarters of respondents stated that they were researchactive, the majority of which (just under two-thirds) having been engaged in 'Research by Practice' in some form; 60 per cent felt that this type of research was not understood by their institution:

There is no understanding of what is involved in the creative process and no value put on this, only on REF-ability [Research Excellence Framework]. (Respondent 2017545344 (University Alliance))

It's a question of language ... I write for a human audience. I am not a scientist. My reflections are not academic enough. The institution has a problem with this. (Respondent 1935532935 (Million+))

... it is very hard to try and get institutions to see actual commissions as research. (Respondent 3326267613 (University Alliance))

It is not valued as equivalent to published peer-reviewed output - even when it is seen by millions of viewers! (Respondent 2022666615 (Million+))

These comments and others suggest that there has been a possible lack of communication between institutions and practitioner staff regarding the specific needs and uses of research outputs in the academy. The language used by several respondents indicates that some have a divergent view of what constitutes academic research, a view that is consistent with Nelson's (2013: 23-47) observations of 'practitioners moving to practitioner-researchers'. This divergence may well be a factor in the shift from the predominantly positive perception at 'welcome' to the increasingly negative perception of how practitioner-academics were viewed by non-practitioner colleagues (apart from those at Arts-focused institutions) discussed earlier.

The last quotation above is of particular note, given the increasing importance of 'impact' in the measurement of the 'value' of research, as exemplified by the specific mention of these in the Research Excellence Framework (REF, 2014) as well as on Research Councils UK funding application forms. Given that part of 'impact' is to raise awareness or effect change based on the reach of a work, the comments suggest that there needs to be more focused dialogue between institutions and their practitioneracademics to ensure that mutually beneficial opportunities are not being missed, particularly since broadcast television and feature film projects can reach significant audiences.

Bell (2006: 90) observed that 'research councils like the AHRC remain nervous about funding creative practice projects such as films ... where the "research value added" component cannot be delineated from the vehicle of the creative practice and evaluated as a separate deliverable'. However, it appears that funding council and government views may have begun to change. Both Barnard's feature documentary The Arbor (2010) and Oppenheimer's The Act of Killing (2012) received production funding from the Arts and Humanities Research Council. More significantly, the AHRC's recent Creative Economy Programme (AHRC, 2017-18) was specifically devised to enable academic-industry collaborations to enhance commercial project development, where success is to be measured in commercial rather than academic terms. Indeed, while details of REF 2021 are still to be confirmed, a recently commissioned report suggests that Research England is likely to use the indicators of 'engagement', 'mentions in non-academic documents and the media', 'employment' and 'financial figures' in assessments of REF case study submissions (Parks et al., 2018). These measures would 
appear to align more readily with those used to assess the success of commercial film or television works than criteria used in 2014, suggesting greater acceptance of commercial practice methods. However, even with an apparent shift in government perspectives on the role of the academy, the impact of commercial activity within it and the value of industry practice, there is currently no evidence that institutional policies or the perceptions of the practitioner-academics themselves (as articulated by the respondents in this study) are changing as well. This is an area for further investigation.

Considering perceptions of Research by Practice within the various types of institutions, percentages suggest a difference between the views of participants from Arts-focused universities and those from other types (see Table 5). However, these differences did not reach statistical significance, most likely due to the small numbers involved (Fisher's Exact, $p=0.20$; chi-square, $p=0.20$ ). To more fully determine whether there is a significant difference, a larger data set is needed.

\section{Table 5: Percentage engaged in 'Research by Practice' who felt that it is understood by their institution}

\begin{tabular}{lc}
\hline Institution type & $\begin{array}{c}\text { Respondents } \\
\% \text { (number) }\end{array}$ \\
\hline Arts-focused & $71(5$ of 7$)$ \\
Former 1994 Group & $50(2$ of 4$)$ \\
Million+ & $46(12$ of 26$)$ \\
University Alliance & $33(5$ of 15$)$ \\
Russell Group & 0 (0 of 4) \\
\hline
\end{tabular}

Of the 95 respondents who stated that they were research-active, only 29 per cent indicated that they were involved in PhD supervision. This is remarkable, in that this is often seen as an important part of academic research activity (Coate et al., 2001), as well as a common consideration for promotion. Possible reasons as to why this number is lower than expected is another area for future investigation.

Several respondents reported that they felt it was difficult to be a non-researchactive academic in their institution. Some expressed this quite strongly:

'Teaching only' in a research-led university like this one is clearly regarded as second-class citizenship among academics. (Respondent 1954700730 (Russell Group))

Life as a non-research academic in a research university is a battle and has worn me down over the years. (Respondent 3369057913 (Russell Group))

Teaching and research contracts? Wow. (Respondent 3318432409 (Million+))

We provide 94 per cent of the faculty's income but the REF FTE [full time equivalent] submission was 40 per cent of the workforce, and they generated less than 4 per cent of the faculty's income. Therefore those in the 'teaching ghetto' finance all the others to progress their academic careers, while we are left at a standstill. (Respondent 3324061951 (Million+))

From these comments and others, it is evident that many survey participants perceived a 'class difference' between those engaged in research and those who were not, with the former being viewed more favourably in their institutions. This is consistent with 
findings of studies such as Burton and Haines (1997), Hannan and Silver (2000) and Taylor (1999) that investigate different aspects of teaching within higher education. Young (2006: 191) is one particularly clear example, where the author states, 'Unanimously, [researchers in this area] report the low status which higher education institutions give to teaching as an activity'.

\section{Involvement with industry}

Nearly two-thirds of respondents indicated that they were still active in industry, although three-quarters of those stated that they needed to fit industry work around academic requirements, just over half without any assistance or accommodation from their institution. This has both presented challenges and been a source of frustration:

To edit a full-length documentary for seven weeks, I have to give up my summer holidays. (Respondent 2022666615 (Million+))

Sometimes [it is] very hard to juggle a fixed timetable against flexible/ expanding media projects. (Respondent 1971374170 (University Alliance))

Projects take much longer as a result of the academic workload, and usually take place in summer. (Respondent 1940591317 (Million+))

I have only been shooting 3 weeks per year - which isn't even my full allocation of research days, but all I can muster. I need to do more to be satisfied in my work. (Respondent 1934230802 (Million+))

It's easier to get a sabbatical to write a chapter than shoot a feature film or make a documentary. Ironic, seeing as a film could provide students with valuable experience, enhancing learning and employability. Film-making is a team experience, writing a chapter isn't. (Respondent 3318173860 $($ Million+))

There was no measurable difference between the type of institution and the likelihood of a participant being active in industry (chi-square $=2.2, p=0.71$ ). However, there was a marked difference between types of institutions in the level of accommodation of professional practice, with Russell Group and Million+ universities being seen as the least supportive of this type of activity, as shown in Table 6 (chi-square $=19.6, p=0.0006$ ).

Table 6: Percentage whose institution made adjustments to accommodate practice

\begin{tabular}{lc}
\hline Institution type & $\begin{array}{c}\text { Respondents } \\
\% \text { (number) }\end{array}$ \\
\hline Former 1994 Group & $88(7$ of 8$)$ \\
University Alliance & $82(14$ of 17$)$ \\
Arts-focused & $43(6$ of 14$)$ \\
Million+ & $32(12$ of 38$)$ \\
Russell Group & $17(1$ of 6$)$ \\
\hline
\end{tabular}

From the results, it is reasonable to infer that, if practice were seen as an important component of department activities, institutions would go to greater lengths to ensure such activity could be readily accommodated, as they do for traditional research. It should be noted that some institutions have actively supported academic-industry collaborations in the production of commercial media projects involving their staff, 
including Research by Practice, but those experiences have been mixed - see Mateer (2018) for a detailed review of feature films created in this manner.

Comments from some participants also suggest that engaging with industry can introduce compromises in other areas of work for the academy:

I have been allowed to take on broadcast work as the experience is seen to be valuable, but I have to fit that around commitments and have taken unpaid leave to do so. You can't make films and teach - the teaching suffers inevitably. (Respondent 1938855447 (Million+))

Overly heavy teaching workloads have meant that I have turned down far more production work than I've been able to accept - some of it highly relevant to my core research interests. (Respondent 1954700730 (Russell Group))

It is a struggle to balance both priorities - shifting timetables and working for two institutions compounds this problem. (Respondent 3323998097 (Arts-focused))

Of the 35 per cent of participants who were no longer involved with industry, the time required by academic work was seen as the major factor by just over 60 per cent. This comment is indicative:

Getting work in the industry is a full-time job, and you have to be available immediately. It's simply not viable with an academic schedule. (Respondent 3329162357 (Former 1994 Group))

\section{Industry views of working in academia}

As noted above, respondents indicated that perceptions of their work in academia by industry colleagues was fairly evenly split, skewing slightly negative. There was no measurable difference based on institutional affiliation. This suggests that the reputations or rankings of institutions have not been greatly considered by those working in media industries.

Interestingly, comments were quite polarized. Several respondents who had received negative perceptions reacted quite strongly:

The phrase 'Those who can, do, and those who can't, teach' is regularly used in my company. (Respondent 3329472720 (Million+))

It isn't counted in the industry, 'you are out!' (Respondent 1955468867 (University Alliance))

They are two separate worlds with two separate languages and ways of understanding. (Respondent 3347201018 (Million+))

Once you leave the industry you are very quickly forgotten especially in a very competitive role such as Director. (Respondent 3329162357 (Former 1994 Group))

Some in industry appear to view practitioner involvement in academia very positively:

They think it must be amazing! (Respondent 3369057913 (Russell Group))

There are an awful lot of people out there in the industry, particularly the older ones, who envy me ... (Respondent 1944580834 (Million+)) 
Usually impressed that I have taken this step. Older colleagues often want to do the same. (Respondent 3324231042 (Arts-focused))

A few participants were more circumspect, and indicated the conflicted feelings many practitioners working in academia appear to feel. This quotation sums those up:

It's not as simple as that ... my industry colleagues have a romantic notion of film schools. And they have a very positive attitude towards me doing this job ... but when they get involved in stuff that I do they are as shocked as I am. Particularly with assessment and the modular nature of the courses ... and are surprised by the talent of students and dedication of staff working in this environment. Good work is made despite the institution ... so views of industry colleagues are mixed. (Respondent 1935532935 (Million+))

\section{Future plans}

Just over half of respondents indicated that they intended to continue to work in both academia and industry. Given the challenges and negative feelings many participants expressed towards working in the academy, it would seem that this is an interesting contradiction. However, comments suggest that many were choosing to stay involved with academia for practical reasons:

I doubt this is a matter of choice for most people but necessity. I doubt if anyone can afford to have a career plan these days. (Respondent 1938855447 (Million+))

The hours, the flexibility and the steady work in academia make it very hard to leave when you have a young family to support. (Respondent 3369057913 (Russell Group))

If the industry provided a stable career I would prefer to work in industry for all or part of my time but I am attracted to academia by the illusory possibilities of professional practice and practice-based research. (Respondent 1934983484 (Million+))

I am finding working as an academic so time consuming that I find it hard to do any practice. However, I don't anticipate that in this market it would make financial sense to leave academia to support myself in the industry again. (Respondent 1934230802 (Million+))

A few expressed resignation about an inability to return to industry at a level meaningful to them. This comment is indicative:

It is a one-way process and as the creative industry is fundamentally ageist it is unlikely I would gain a senior managerial role back in the industry equivalent to my role at the university. (Respondent 2022666615 (Million+))

Those who did indicate that they planned to leave academia entirely expressed strong dissatisfaction with the academy. These comments are reflective of the sentiments of this group:

Education has become very unpleasant and difficult for any intellectual pursuit, or real teaching. (Respondent 1942226482 (University Alliance))

I would like to have ticked the box ... to continue working in both the industry and academia ... but the nature of institutional academia makes 
that impossible - the majority of work I have as an academic has very little to do with film-making or teaching film-making, it leaves me little time for the things that are important. This has been a big shock to me. (Respondent 1935532935 (Million+))

It's crucial that we have media practitioners in this area, but also that we have staff who understand the often Kafkaesque workings of an $\mathrm{HE}$ institution. For this reason staff on PT [part-time] teaching-only contracts who still work in the industry have a huge part to play and should be given more respect and acknowledgement. (Respondent 1935483006 (Million+))

\section{Conclusions}

I undertook this study initially with the arguably selfish objective of seeing whether the experiences of film and television practitioners working in UK higher education were similar to my own. Results from the survey conducted in 2012 were striking, so I undertook a follow-up survey in 2014 , both to validate the findings of the first survey and to gain additional insight into the issues reported. The high response rate for the surveys and the strong sentiments expressed by the participants suggest that not only were my mixed experiences in the academy common but also that they represent direct evidence of the continued impact of the theory/practice divide. The surveys show that many practitioner-academics perceive a 'two-tier' system in which their experience and expertise from working in industry is not fully valued by the academy despite its relevance to furthering institutional teaching objectives, particularly enhancing employability. The perception of those undertaking Research by Practice was that it is still often seen as inferior to more traditional forms of research. Yet, changes in industry and a belief in the relative security of academia have led many practitioneracademics to put up with what several have reported to be unfair treatment. Likewise, $\mathrm{HE}$ institutions have not seemed to recognize the impact of negative staff interactions and their effect on staff productivity. Participant comments suggest that they felt the relationship between the academy and practitioner-academics was not likely to change.

It has been four years since the last survey was completed, which raises the question of whether the situation for film and television practitioner-academics is any different today. To answer this question fully requires updated information from the practitioner-academics themselves but there are some indicators that suggest that the institutional rigidity participants noted may be beginning to change, mainly due to a range of economic pressures. The notion of a 'triple helix' - the increasingly interdependent relationship between government, industry and academia first discussed by Etzkowitz and Leydesdorff (1995) two decades ago - appears to be materializing rapidly. Along with the government's reductionist emphasis on 'employability' and 'value' in education, research funding structures for supporting higher education are changing, with new requirements to demonstrate economic benefit. Central to this is commercial engagement, as exemplified by an expansion in the range of Knowledge Transfer Partnerships supported by Innovate UK, particularly in the arts, and major initiatives such as the AHRC's Creative Economy Programme (discussed in the 'Research activity' section above). Related to this, models of Research by Practice are becoming more clearly formalized and increasingly recognized, not only by the government (for REF 2021, as discussed above) but also within the academy through the establishment of championing bodies such as PRAG-UK (n.d.). At institutional level, industry engagement has begun to be formalized by some universities. One example is the University of York, where the role of Pro-Vice-Chancellor for Partnerships and 
Knowledge Exchange was recently established alongside a new university committee dedicated to industrial engagement that runs in parallel to the university's research committee. This suggests a significant institutional commitment to embracing the commercial sector, considering it on an equal footing with traditional research. Central to all of these initiatives is the need to bridge academia and industry cultures and harmonize objectives. Practitioner-academics are clearly well suited to this, which would suggest that the bias and systematic disadvantaging that several respondents reported could become less common.

However, these potential shifts in perspective centre predominantly on research, and a significant number of media practitioner-academics are teaching only. Additional performance measures introduced by the government, such as the Teaching Excellence Framework (DfE, 2016), are putting pressure on HE institutions to demonstrate the efficacy of teaching staff, often through the insistence that academics have advanced degrees (usually PhDs), which is a particular concern noted by respondents. Likewise, UK higher education is in an unprecedented state of flux, particularly with ongoing debates about core funding for universities, including changing tuition fees. There are great uncertainties surrounding Brexit that threaten to affect the entire range of institutional activities, the concerns of the University of Warwick highlighted in a Times Higher Education article being a prime example (Morgan, 2018). Both the data from the surveys and these current trends seem to support Winston's (2011: 195) contention that the use of practitioners as teachers is (and may remain) a marriage of convenience:

\begin{abstract}
Why are they hiring people (scandalously unacademic!!) whose only value is the small matter of them knowing how to teach practice on the basis of their own experience? ... The despised practitioner is made not more happy with her knowing that without her efforts the finances of the university's media education operation (and the 'area studies' department in which it is often embedded) would collapse. The institution, also understanding this, can be nevertheless ever more adamant that insistence on its traditional ways and 'standards' is justified.
\end{abstract}

On balance, it would seem that little real progress has been made in redressing the theory/practice divide since Winston wrote his article, although further work is required to determine this more fully. Additional surveys of practitioner-academics, as well as their non-practitioner colleagues and institutional leaders, are needed to try to gain a better understanding of current attitudes towards the academy and the different types of people and activities that now comprise it. I argue that only when universities review their policies, working practices and institutional attitudes towards industry can they truly make the most of what practitioners can offer and begin to close the theory/ practice divide, to the benefit of all. The emergence of changing attitudes towards industrial engagement in the academy is certainly welcome. However, based on my experiences, and those of others as reflected in the surveys, it seems there is still a long way to go.

\title{
Acknowledgements
}

Thanks to Dr Jean McKendree for her advice on statistical analysis methods. 


\section{Notes on the contributor}

John Mateer has been working in film and television for more than 30 years, and as an academic for over 18 . He recently worked as executive producer on the feature film The Knife That Killed Me (UK 2014, Universal Pictures) and as visual effects producer for Macbeth (UK 2018, GSP Studios). He was a founding member of the Department of Theatre, Film and Television at the University of York, where he designed (and currently teaches on) four film and television production courses, as well as being heavily involved in the design of the department's bespoke building. He is a graduate of the American Film Institute Conservatory and New York University's Tisch School of the Arts.

\section{Filmography}

The Act of Killing (UK/DK/NO 2012, Joshua Oppenheimer)

The Arbor (UK 2010, Clio Barnard)

\section{References}

AHRC Creative Economy Programme (2017-18) 'Creative Economy Programme'. Online. https://ceprogramme.com/about/\#cep (accessed 1 January 2019).

Aidelman, N. and Colell, L. (2018) 'Transmitting cinema: Some proposals for our time'. Film Education Journal, 1 (2), 147-62.

Ashforth, B.E. (2000) Role Transitions in Organizational Life: An identity-based perspective. New York: Routledge.

Ashton, D. (2013) 'Industry practitioners in higher education: Values, identities and cultural work'. In Ashton, D. and Noonan, C. (eds) Cultural Work and Higher Education. Basingstoke: Palgrave Macmillan, 172-92.

Bachmann, A. and Zahn, M. (2018) 'Film education as a multiplicity of practices: A media-ecological perspective'. Film Education Journal, 1 (1), 78-89.

Bell, D. (2004) 'Practice makes perfect? Film and media studies and the challenge of creative practice'. Media, Culture and Society, 26 (5), 737-49.

Bell, D. (2006) 'Creative film and media practice as research: In pursuit of that obscure object of knowledge'. Journal of Media Practice, 7 (2), 85-100.

Bergala, A. (2016) The Cinema Hypothesis: Teaching cinema in the classroom and beyond (FilmmuseumSynemaPublikationen 28). Trans. Whittle, M. Vienna: Austrian Film Museum.

BFI Southbank (2017) The Cinema Hypothesis - Alian Bergala Symposium [sic.] [video]. Online. www.youtube.com/watch?v=COH74quOWJ8 (accessed 1 January 2019).

Boswell, W.R., Boudreau, J.W. and Tichy, J. (2005) 'The relationship between employee job change and job satisfaction: The honeymoon-hangover effect'. Journal of Applied Psychology, 90 (5), 882-92.

Burton, L. and Haines, C. (1997) 'Innovation in teaching and assessing mathematics at university level'. Teaching in Higher Education, 2 (3), 273-93.

Chambers, J. (2018) 'Towards an open cinema: Revisiting Alain Bergala's The Cinema Hypothesis within a global field of film education'. Film Education Journal, 1 (1), 35-50.

Clews, D. and Mallinder, S. (2010) Looking Out: Effective engagements with creative and cultural enterprise: Key report. Brighton: Art Design Media Subject Centre. Online. https://tinyurl.com/ yy2uouse (accessed 14 February 2019).

Coate, K., Barnett, R. and Williams, G. (2001) 'Relationships between teaching and research in higher education in England'. Higher Education Quarterly, 55 (2), 158-74.

Crook, T. (2015) 'Practice and theory wars in media and cultural studies'. Proceedings of the Association of Media Practice Academics Second Annual Conference, Birmingham City University, Birmingham. Online. https://mediapracticeacademics.com/tag/john-hartley/ (accessed 13 February 2019).

DCMS (Department for Digital, Culture, Media and Sport) and BEIS (Department for Business, Energy and Industrial Strategy) (2018) 'Major new research investment set to provide boost for UK's Creative Industries'. Press release, 13 November. Online. https://tinyurl.com/y6mccrd5 (accessed 14 February 2019). 
Dent, T. (2016) 'Feeling Devalued: The creative industries, motherhood, gender and class inequality'. Unpublished PhD thesis, Bournemouth University.

Dex, S., Willis, J., Paterson, R. and Sheppard, E. (2000) 'Freelance workers and contract uncertainty: The effects of contractual changes in the television industry'. Work, Employment and Society, 14 (2), 283-305.

DfE (Department for Education) (2016) 'Policy paper: Teaching Excellence Framework factsheet'. Online. http://tinyurl.com/jeaxyhq (accessed 13 February 2019).

Etzkowitz, H. and Leydesdorff, L. (1995) 'The triple helix - university-industry-government relations: A laboratory for knowledge based economic development'. EASST Review, 14 (1), 14-19.

Feldman, D.C. (1981) 'The multiple socialization of organization members'. Academy of Management Review, 6 (2), 309-18.

Hannan, A. and Silver, H. (2000) Innovating in Higher Education: Teaching, learning and institutional cultures. Buckingham: SRHE and Open University Press.

Hesmondhalgh, D. and Baker, S. (2010) '"A very complicated version of freedom": Conditions and experiences of creative labour in three cultural industries'. Poetics, 38 (1), 4-20.

Jokisaari, M. and Nurmi, J.-E. (2009) 'Change in newcomers' supervisor support and socialization outcomes after organizational entry'. Academy of Management Journal, 52 (3), 527-44.

Lodahl, T.M. and Kejner, M. (1965) 'The definition and measurement of job involvement'. Journal of Applied Psychology, 49 (1), 24-33.

Mateer, J. (2018) 'A Fistful of Dollars or The Sting? Considering academic-industry collaborations in the production of feature films'. Media Practice and Education, 19 (2), 139-58.

Morgan, J. (2018) 'Warwick v-c fears "nightmare" Brexit scenarios'. Times Higher Education, 12 November. Online. https://tinyurl.com/yxkat3w3 (accessed 14 February 2019).

Myer, C. (ed.) (2011) Critical Cinema: Beyond the theory of practice. London: Wallflower Press.

Nelson, R. (ed.) (2013) Practice as Research in the Arts: Principles, protocols, pedagogies, resistances. Basingstoke: Palgrave Macmillan.

Parks, S., loppolo, B., Stepanek, M. and Gunashekar, S. (2018) Guidance for Standardising Quantitative Indicators of Impact within REF Case Studies. Cambridge: RAND Europe. Online. www.rand.org/pubs/research_reports/RR2463.html (accessed 1 January 2019).

Parmar, N.A. (2010) Media Practitioners Engaging with Higher Education (Looking Out Case Study). Online. https://tinyurl.com/yy2b4hvv (accessed 14 February 2019).

Petric, V. (1974) 'From a written film history to a visual film history'. Cinema Journal, 14 (2), $20-4$.

Petrie, D. (2011) 'Theory/practice and the British film conservatoire'. Journal of Media Practice, $12(2), 125-38$.

Petrie, D. and Stoneman, R. (2014) Educating Film-Makers: Past, present and future. Bristol: Intellect.

PRAG-UK (Practice Research Advisory Group) (n.d.) 'PRAG-UK'. Online. https://prag-uk.org/ (accessed 1 January 2019).

REF (Research Excellence Framework) (2014) 'Assessment criteria and level definitions'. Online. http://tinyurl.com/y5r5skjp (accessed 13 February 2019).

Taylor, P. G. (1999) Making Sense of Academic Life: Academics, universities and change. Buckingham: SRHE and Open University Press.

Vroom, V.H. (1962) 'Ego-involvement, job satisfaction, and job performance'. Personnel Psychology, $15(2), 159-77$.

Winston, B. (2011) 'Theory for practice: Ceci n'est pas l'épistémologie'. In Myer, C. (ed.) Critical Cinema: Beyond the theory of practice. London: Wallflower Press, 191-200.

Young, P. (2006) 'Out of balance: Lecturers' perceptions of differential status and rewards in relation to teaching and research'. Teaching in Higher Education, 11 (2), 191-202. 